\title{
A SYSTEMATIC REVIEW AND META-ANALYSIS OF THE EFFECTIVENESS OF SURGICAL DECOMPRESSION IN TREATING PATIENTS WITH MALIGNANT MIDDLE CEREBRAL ARTERY INFARCTION
}

Wisha Gul ${ }^{1,2}$, Heidi R Fuller ${ }^{1,3}$, Helen Wright ${ }^{1,4}$, Jon $\operatorname{Sen}^{5,6^{*}}$

${ }^{1}$ Postgraduate Medicine, Keele University, Staffordshire, ST5 5BG; ${ }^{2}$ Lancaster Medical School, Lancaster University, Lancaster, LA14YW; ${ }^{3}$ Wolfson Centre for Inherited Neuromuscular Disease, RJAH Orthopaedic Hospital, Oswestry, SY10 7AG, UK; ${ }^{4}$ Projects and Information Data Analyst, University Hospitals of North Midlands NHS Trust, Newcastle Rd, Stoke-on-Trent ST4 6QG; ${ }^{5}$ Neurosurgery Fellow, Harley Street Clinic, 35 Weymouth Street, London W1G 8BJ; ${ }^{6}$ Clinical Lecturer, Institute of Applied Clinical Sciences, Keele University, Guy Hilton Research Centre, Staffordshire ST4 7QB.

* Corresponding author

Email: j.sen@keele.ac.uk

Telephone: Work +44 (0) 1782679948 Mobile +44 (0) 7770953446

Fax: +44 (0) 1782734238

Keywords: decompressive surgery, hemicraniectomy, malignant, middle cerebral artery infarction, traumatic brain injury, increased intracranial pressure

Highest academic degrees:

Wisha Gul: MMedSci

Heidi R Fuller: $\quad$ Ph. D

Helen Wright: $\quad$ MSc

Jon Sen: $\quad$ Ph. D

Word count: 2907

References count: 40 


\section{Abbreviations}

\begin{tabular}{|c|c|}
\hline ABI & Acute Brain Injury \\
\hline BMT & Best Medical Therapy \\
\hline CI & Confidence Interval \\
\hline CSF & Cerebrospinal fluid \\
\hline DC & Decompressive craniectomy \\
\hline GCS & Glasgow Coma Scale \\
\hline GOS & Glasgow Outcome Scale \\
\hline GOS-E & Extended Glasgow Outcome Scale \\
\hline ICHn & Intracranial hypertension \\
\hline ICP & Intracranial pressure \\
\hline IV & Inverse variance \\
\hline MCI & Malignant middle-cerebral-artery infarction \\
\hline mRS & Modified Rankin Scale \\
\hline NOS & Newcastle- Ottawa Scale \\
\hline NRT & Non-randomised trials \\
\hline OR & Odds ratio \\
\hline PICO & population, intervention, control, and outcomes \\
\hline QoL & Quality of Life \\
\hline RCT & Randomised controlled trials \\
\hline RoB & Risk of bias \\
\hline
\end{tabular}




\begin{abstract}
Background Malignant infarction of the middle-cerebral-artery (MCI) is life threatening. It is associated with a mortality as high as $80 \%$ and survival often at the expense of serious disability. Limited success of medical therapies has resulted in decompressive craniectomy (DC) being increasingly used as a treatment for MCI, though evidence of its efficacy is inconclusive. In this study, the efficacy of DC in improving survival, or survival free of severe disability, was assessed.
\end{abstract}

Methods A meta-analysis was performed to approximate the efficacy of DC for treating MCI, considering age and time-to-surgery. A systematic literature review was conducted on Medline, Embase and Cochrane library databases to 01 August 2018. Death and severe disability at 3, 6, 12 and 36 months follow-up were assessed, comparing best medical therapy with DC.

Results 18 studies were eligible for inclusion and represented 987 individuals who received DC. Nine of these were RCTs ( $n=374$ DC). Early DC ( $<48$ h from onset of stroke) reduced mortality $\quad(\mathrm{OR}=0.18, \quad 95 \% \mathrm{CI}=0.11, \quad 0.29 ; \quad \mathrm{P}<0.00001) \quad$ but not unfavourable outcome (modified Rankin Scale $(\mathrm{mRS})>4)(\mathrm{OR}=1.38,95 \% \mathrm{CI}=0.47,4.11 ; \mathrm{P}=0.56)$ at 12 months follow-up. This survival benefit was maintained regardless of age.

Conclusion Early DC reduces mortality but does not appear to improve favourable outcomes in patients aged younger or older than 60 years following MCI. RCTs incorporating quality of life assessments are warranted for MCI patients, in addition to defining the optimal timing and benefits of DC in older patients. 


\section{Funding None}

\section{INTRODUCTION}

Acute brain injury (ABI), defined as injury to the brain that occurs after birth, is one of the leading causes of death and disability in adults worldwide. ${ }^{1,2}$ Malignant stroke is a common cause of ABI. In a subgroup of patients with supra-tentorial stroke (approximately 1-10\%), malignant middle cerebral artery infarctions (MCI) can occur. ${ }^{3}$ These patients develop space-occupying brain oedema resulting in raised intracranial pressure (ICP), with subsequent ischaemic cell death and brain herniation. The prognosis is poor, with mortality as high as $70-80 \%$ and majority of survivors left with severe disabilities. ${ }^{4,5}$

The poor outcome is, at least in part, attributed to intracranial hypertension (ICHn), defined as ICP greater than $15-20 \mathrm{mmHg} .{ }^{6}$ Conventional treatment worldwide is aimed at reducing ICP using head elevation, osmotic agents, controlled hyperventilation, hypothermia and sedatives. $^{7}$ Once brain swelling is sufficient to produce clinical and radiological signs, however, case-fatality is higher, despite optimal medical treatment. ${ }^{8,9}$ Decompressive craniectomy (DC), with removal of cranium and subsequent durotomy/duroplasty, is an aggressive approach shown to reduce ICP and improve blood flow to ischaemic tissue in patients with refractory ICHn. ${ }^{10,11}$

Although DC is effective in reducing ICP it is accompanied by a myriad of non-trivial complications. ${ }^{12}$ More importantly, there is a concern that survivors suffer permanent severe disability. A pooled analysis of randomised controlled trials (RCTs) showed that DC significantly reduced mortality and improved favourable outcome defined as modified Rankin scale $(\mathrm{mRS}) \leq 3$ in patients with MCI. ${ }^{13}$ However, the inclusion of HAMLET trial showed a non-significant benefit associated with DC $(\mathrm{mRS} \leq 4) .{ }^{14}$ Moreover, important questions regarding the effect of patient age, timing of surgery and the issue of defining a 
'favourable' outcome remain unclear.

The present systematic review and meta-analysis of all available studies aimed to establish the effectiveness of DC on mortality and associated long-term outcomes in patients following MCI, with special consideration of patient age and optimum timing for surgery.

\section{METHODS}

A systematic literature review was conducted on MEDLINE, EMBASE, Cochrane library database and Controlled Trials metaRegister to define the role of DC in patients with MCI. Details of the search strategies that incorporated search criteria used by a previous Cochrane review ${ }^{14}$ are given in Supplementary File 1. The last search update was $1^{\text {st }}$ of August 2018. The titles, abstracts and keywords of relevant articles were examined to assess for eligibility, followed by screening of reference lists from retrieved articles to identify additional studies. The study selection process was performed according to the guidelines of PRISMA (Preferred Reporting Items for Systematic Reviews and Meta-Analyses) and documented using a PRISMA flow diagram (Figure 1). ${ }^{15}$

\section{Study Eligibility}

All clinical trials were eligible for inclusion, with no restriction on language or time of publication. The inclusion criteria were: 1) studies including adult patients over 18 years of age with MCI. MCI was defined as patients with acute ischaemic infarction with spaceoccupying cerebral oedema, as evident on radiology; 2) studies comparing DC to medical treatment alone as control. Medical treatment or best medical therapy (BMT) was defined as non-surgical therapies to control ICP such as hyperosmolar solutions, sedation and paralysis, hyperventilation, barbiturates, and moderate hypothermia. Cerebrospinal fluid (CSF) drainage in patients with ICP monitoring was also regarded as a medical therapy ${ }^{6} ; 3$ ) 
primary outcomes assessed were death and disability defined by mRS or Glasgow outcome scale (GOS)/ extended-GOS (GOS-E) (if mRS score was unavailable), or a description of level of independence, at 3, 6, 12 or 36 months follow-up.

Exclusion criteria were: 1) no comparison with medical treatment group; 2) unavailability of outcome data in an extractable format such as odds ratios (OR), relative risks, or results from which these could be calculated, at 3, 6, 12, or 36 months follow-up; and 3) reviews, metaanalysis, guidelines, case reports, letters to editor, comments, duplicate studies.

\section{Data Extraction}

The following data were extracted and tabulated from MCI studies into standardised data extraction forms by two authors independently: study design, sample size, patient eligibility criteria, patient demographics such as age and gender, surgical procedure, National Institute of Health Stroke Scale (NIHSS) score, vascular territories and site of infarction, presence of preoperative clinical signs of herniation, time to surgical decompression, neurological outcomes as measured by $\mathrm{mRS}$ or GOS, mortality rates and duration of follow-up. Discrepancies were resolved by discussion between all authors.

\section{Quality assessment}

Each study underwent a quality assessment by two authors independently. For the RCTs the Cochrane Collaboration's risk of bias (RoB) tool ${ }^{16}$ was used to assess selection bias, attrition bias, performance bias, detection bias, and reporting bias. The limitation of NRTs falling short of full randomisation when allocating individuals to treatment group is recognised, and a careful assessment of RoB in NRT methodology was conducted. In particular, assessment 
of selection bias, bias due to confounding, and bias in measurement of interventions, was made using a modified version of Newcastle-Ottawa scale (NOS). ${ }^{17}$

\section{Outcome}

The primary outcome measures evaluated in this meta-analysis were: 1) death at 3 months, 6 months, 12 months and 36 months for MCI patients undergoing DC or BMT, and 2) unfavourable outcome defined as mRS score of $>4 .{ }^{18}$. Conventionally, an mRS score of 4 is included in the unfavourable outcome category and defines moderately severe disability where patients require assistance with walking and attending own bodily needs. An mRS of 5 indicates severe disability; bedridden, incontinent, requiring nursing care and attention. Given that survival following MCI with no or slight disability is rare, investigators of recent RCTs include an mRS of 4 in the favourable outcome category. ${ }^{19}$ Thus, data processed in the present study reflects this change for purposes of standardisation.

\section{Statistical analysis}

A summary of dichotomous outcome data in the form of odds ratios (ORs) and their corresponding 95\% confidence intervals (CIs) were calculated. These were combined by a random effects meta-analysis model using the inverse variance (IV) method for pooled OR, followed by the Z-test to evaluate statistical significance (a p-value of less than 0.05 was considered statistically significant). The heterogeneity between studies was assessed using Chi-squared statistical test and $\mathrm{I}^{2}$ statistic, where a $\mathrm{p}<0.10$ was considered to be statistically

significant. $\mathrm{I}^{2}$ values up to $60 \%$ referred to moderate heterogeneity. ${ }^{20}$ Sensitivity analyses were performed to investigate heterogeneity for all statistically significant findings. Assessment of publication bias was conducted by qualitative evaluation of funnel plots for asymmetry. All statistical analyses were performed using Review Manager 5.3 (RevMan) (Nordic Cochrane Centre) and reviewed by an information data analyst (HW). 


\section{RESULTS}

Figure 1 presents the process from study identification (24,950 records) to selection. Of the 24,950 records identified initially, the majority were excluded because they were reviews, case reports, duplicates, comments or irrelevant patient meet our population, intervention, control, and outcomes (PICO) criteria. Further, full texts were analysed and 18 studies comprising of nine RCTs and nine NRTs satisfied our inclusion criteria. These included 497 patients in the surgery group and 486 patients in the conservative group. Of these nine were RCTs (379 patients) and nine were NRTs with (613 patients). The main study characteristics are summarised in Table 1.

Assessments for RoB in nine RCTs and nine NRTs are summarised in Supplementary Table S1 and S2. Briefly, randomisation methods were adequately described in eight studies and allocation concealment in two studies. The main issues with RCTs were in reference to lack of allocation concealment, blinding of outcome assessment, and early termination of trials due to observation of large effects early. ${ }^{12,13,19,21}$ Only 12 patients in the MCI studies ${ }^{19,22,23}$ were lost to follow up. Therefore, no attrition adjustments were required. The assessment of RoB in NRTs showed minimal risk of bias in all studies $(>6 / 9$ points on the NewcastleOttawa Scale).

\section{Decompressive Craniectomy in Malignant Cerebral Infarction.}

Primary outcome: death at the end of follow-up

Figure 2a presents a forest plot showing the pooled results of 18 studies for risk of death associated with DC versus BMT in patients with MCI. The pooled results of five studies at 3 
months (OR 0.17 95\%CI 0.07-0.44; $\mathrm{p}=0.0002 ; \mathrm{I}^{2}=40 \%$ ), 11 studies at 6 months (OR 0.25 95\%CI $0.14-0.43 ; \mathrm{p}<0.00001 ; \mathrm{I}^{2}=54 \%$ ), eight studies at 12 months (OR $0.1895 \%$ CI 0.11 $0.29 ; \mathrm{p}<0.00001 ; \mathrm{I}^{2}=0 \%$ ), and one study at 36 months (OR $\left.0.2195 \% \mathrm{CI} 0.07-0.61\right) ; \mathrm{p}=$ 0.004) suggest a statistically significant association between DC and reduced risk of death.

\section{Primary outcome measure: unfavourable outcome}

A forest plot showing the pooled results for risk of unfavourable outcome (defined as mRS $=5$ ) associated with DC versus BMT in patients with MCI is shown in Figure 2b. The pooled results of three studies at 3 months (OR $0.5395 \% \mathrm{CI} 0.19-1.46 ; \mathrm{p}=0.22 ; \mathrm{I}^{2}=0 ; \mathrm{p}=0.22$ ), eight studies at 6 months (OR 1.03 95\%CI 0.43-2.47; $\mathrm{p}=0.94 ; \mathrm{I}^{2}=58 \%$ ), and seven studies at 12 months (OR 1.38 95\%CI 0.47-4.11; $\left.\mathrm{p}=0.56 ; \mathrm{I}^{2}=39 \%\right)$ suggested there was no significant difference between DC and BMT in terms of proportion of survivors with an unfavourable outcome. One study at 3 years also reflected this trend.

\section{Subgroup analysis of outcomes at 6 months: age $<60$ versus age $>60$ years}

Figure 3 presents the subgroup analysis, stratified by age. DC significantly reduced mortality in younger patients (OR $0.2895 \%$ CI $0.15,0.54 ; \mathrm{p}=0.0001 ; \mathrm{I}^{2}=12 \%$ ) and older patients OR $0.1495 \%$ CI $0.07,0.28 ; \mathrm{p}<0.00001 ; \mathrm{I} 210 \%$ ) at 6 months follow-up. No significant difference in unfavourable outcome was found in younger (OR $0.9995 \%$ CI $0.18,5.53 ; \mathrm{p}=0.99 ; \mathrm{I}^{2}=$ $61 \%$ ) or older patients (OR $0.6695 \%$ CI $0.24,1.85 ; \mathrm{p}=0.43 ; \mathrm{I}^{2}=0 \%$ ).

Subgroup analysis of outcomes associated with early ( $<48$ hours) versus late DC ( $>48$ hours)

Table 2 presents the subgroup analysis, stratified by timing of DC. Early DC ( $<48$ hours) significantly reduced mortality at 3 months follow up (OR $0.10,95 \% \mathrm{CI} \quad 0.04,0.23$, 
$\mathrm{p}<0.00001$ ), 6 months follow up (OR 0.22 95\%CI 0.13, 0.39, $\mathrm{p}<0.00001$ ), 12 months followup (OR 0.15, 95\%CI 0.09, 0.26, $\mathrm{p}<0.00001$ ), and 3 years follow-up (OR 0.09 95\%CI 0.02, $0.40, \mathrm{p}=0.002$ ). However, early DC did not demonstrate a significant decrease in proportion of patients with an unfavourable outcome at any of the follow up periods. DC performed after 48 hours following MCI was not associated with improved outcomes at any of the follow up periods.

Heterogeneity and sensitivity analyses for mortality and unfavourable outcome in MCI patients

A sensitivity analysis of the MCI studies was performed to investigate the heterogeneous results at 6 months for mortality $\left(\mathrm{I}^{2}=54 \%\right)$ and unfavourable outcome $\left(\mathrm{I}^{2}=58 \%\right)$ (Table 3$)$. Exclusion of NRTs resulted in reduction of heterogeneity of pooled results for both mortality $\left(I^{2}=18 \%\right)$ and unfavourable outcome $\left(I^{2}=0 \%\right)$ to acceptable levels.

\section{Assessment of publication bias}

Assessment of publication bias was carried out using funnel plots. The OR were plotted on a logarithmic scale to ensure that the results of same magnitude but opposite directions were spaced equidistant from 1.0. The funnel plots did not demonstrate any obvious asymmetry (Figure 4).

\section{DISCUSSION}

Evidence from eight studies in our pooled analysis demonstrates a significant survival advantage associated with DC in patients of all ages, when performed within 48 hours of onset of stroke. However, early DC may not reduce poor functional outcome in survivors, 
and DC performed after this time may not reduce mortality or unfavourable functional outcome.

This present analysis included a larger number of RCTs than previous meta-analyses that showed DC improved survival and functional outcome $(\mathrm{mRS} \leq 3)$ in patients with MCI but had a non-significant increase in proportion survivors with a favourable outcome defined as $\mathrm{mRS} \leq 4 .{ }^{13,24}$ Moreover, the definition of unfavourable outcome in this study (mRS $>4$ ) was consistent with recent trials. ${ }^{13,16,25}$ Although an $\mathrm{mRS}$ of 4 is usually identified as an unfavourable outcome, it is argued that considering the severity of a condition like MCI, recovery back to an mRS score of 1 or 2 is highly unlikely. Thus, we included an mRS of 4 in the favourable outcome category, with results showing that early DC significantly reduced mortality but not unfavourable outcome at the end of follow-up.

Importantly, outcome definition by researchers based on scales with a strong emphasis on motor functions may not reflect what is acceptable to the patient. ${ }^{27}$ Thus, a more appropriate approach may involve conducting QoL assessments. A recent systematic review of QoL of patients following DC reported that most disabled patients $(\mathrm{mRS}>3)$ and carers were satisfied with their life and would opt to have the procedure again. ${ }^{28,29}$ In addition, an analysis of quality-adjusted life-years (QALYS) in patients with MCI, reported more QALYS achieved with DC compared to BMT. ${ }^{30}$ QoL assessments were lacking and of poor quality in the included studies. In addition, the QoL assessments in included RCTs were limited to patients that did not suffer from significant aphasia and neurological deficits. ${ }^{13,19,21,21}$ Future studies that consider QoL and psychological states of patients are therefore warranted.

The subgroup analysis stratified by age demonstrated a survival advantage in all age groups 
but did not find a significant association between DC and poor functional outcome. Previous meta-analyses have suggested age to be a strong predictor of poor functional outcome (mRS $\geq$ 4) after DC in older patients. ${ }^{31,32}$ The contrasting result could be due to the small number of studies in the present analysis that included older patients and the corresponding definition of 'older'. For example, some studies defined older patients as $>60$ years, whilst others as $>70$ years, resulting in exclusion of patients between 60 and 70 years of age. ${ }^{33}$ The DESTINY II trial provides the strongest evidence so far for DC in older patients. Although case fatality was comparable with younger patients, functional outcome was worse in the older patients compared to the younger group in previous trials (19\% versus $4 \%) .{ }^{24}$ Together, these results suggest that higher age may be an important predictor of poor outcome, though further studies are warranted to determine an age threshold, if one exists, for MCI patients.

The timing of surgery is another important factor determining outcomes after MCI. Our analysis suggests that late DC ( $>48$ hours) may not improve outcomes in MCI patients. This may be due to cerebral oedema increasing over time, reaching its peak and typically leading to death within $72-96$ hours ${ }^{34}$ thus, rendering later decompressive surgery ineffective. Notably, the HAMLET and HeADDFIRST trials allowed patients to receive DC up to 96 hours. In these patients, no significant benefits were associated with later DC. Interestingly, in the HAMLET trial the mortality rate in the control group was significantly lower than the early DC group suggesting an underlying bias in assigning patients to the later DC group. Often patients undergoing surgery early do so because of rapid clinical deterioration. As such, pre-treatment prognostic factors may be accountable for the apparent lack of effectiveness of delayed DC. In addition, the lack of time subgroup analysis in HeADDFIRST trial makes the efficacy of delayed DC uncertain. ${ }^{35}$ Accordingly, further randomised comparative studies are required to establish the effectiveness of delayed DC. Yet, since the effectiveness of early DC has been established, there is currently no reason to 
employ a watchful waiting approach (waiting for patient to deteriorate clinically) following a diagnosis of MCI.

Some limitations of this study should be considered. First, the outcomes were based on mRS and GOS scales which neglected psychosocial functions and QoL. Second, the outcome assessment was not fully blinded in any study, which may have resulted in a degree of observer bias (though some trials did use partial blinding and combining the results of these trials argues against any major bias). Third, due to the small number of patients included in each individual trial, the conclusions derived from subgroup analyses on expected prognostic factors, such as age and timing to intervention, are not sufficiently powered to show quantitative differences between treatment effects. Fourth, although the technique of DC was standardised in most studies, the medical treatment was not consistent, and often left to the discretion of the attending physician. In the HAMLET trial for example, more patients in the control arm received osmotherapy than in the DC arm. Similarly, more DC patients were cared for in an NCC unit than control group. However, if osmotherapy was significantly effective, the outcomes differences between groups would have been smaller and insignificant.

\section{CONCLUSIONS}

Despite these limitations, this meta-analysis demonstrated a survival benefit associated with hemicraniectomy in patients with MCI both under and over the age of 60 years. Yet, there was no significant difference favouring DC over BMT in terms of unfavourable outcome. As such, whether DC should be performed in patients over the age of 60 years remains controversial. Nonetheless, the likelihood of patients undergoing surgery is expected to increase. This comes with expected rise in morbidity and associated care burden. For 
clinicians, although challenging, it is imperative to communicate the potential range of outcomes and the expected QoL. Large, multicentre RCTs are required to determine efficacy of DC in older patients. These should incorporate long-term QoL assessment in addition to mortality and disability.

Importantly, much can be learned about DC from MCI trials for other causes of ABI, as it is the only ABI condition with numerous RCTs and reviews. Despite this, the issue of benefit of DC has remained a contentious topic and perhaps RCTs may not be the optimal research methodology to address these questions. Continued prospective data collection for assessment of type and timing of DC in patients with different causes of ABI are recommended. Individual units across the UK could all collect such data on a nationally agreed/ approved database.

\section{Acknowledgements}

We would like to thank colleagues and staff at the Postgraduate Medicine department at Keele University for their support with the completion of this study. We also thank Dr Monte A. Gates, senior lecturer in Medicine and Neuroscience at Keele University, for peer reviewing the project proposal process.

\section{Declaration of interests}

We declare no competing interests.

\section{Contributions}

WG and JS designed and oversaw the study. WG conducted the meta-analyses and in conjunction with JS did the primary validation and interpretation of data. WG wrote the 
paper, with HF contributing to substantial edits. WG participated in the statistical analyses whilst HW supervised the process. All authors contributed and critically reviewed the final version of the manuscript.

\section{REFERENCES}

1. Greenwald B, Burnett D, Miller M. Congenital and acquired brain injury. 1. Brain injury: epidemiology and pathophysiology. Am Arch Rehabil Ther. 2003; 84(3 Suppl 1): p. S3-7.

2. Heinsius T, Bogousslavsky J, Van Melle G. Large infarcts in the middle cerebral artery territory. Etiology and outcome patterns. Neurology. 1998; 50(2): p. 341-50.

3. Hacke W, Schwab S, Horn M, Spranger M, De Georgia M, von Kummer R. Malignant middle cerebral artery territory infarction: clinical course and prognostic signs. Arch Neurol. 1996; 53(4): p. 309-15.4.

4. Berrouschot J, Sterker M, Bettin S, Koster J, Schneider D. Mortality of space-occupying ('malignant') middle cerebral artery infarction under conservative intensive care. Intensive Care Med. 1998; 24(6): p. 620-23.

5. Marmarou A, Anderson R, Ward J, et al. Impact of ICP instability and hypotension on outcome in patients with severe head injury. J Neurosurg. 1991; 75(1S): p. S59-S66.

6. Carney N, Totten A, O'Reilly C, et al. Guidelines for the Management of SevereTraumatic Brain Injury, Fourth Edition. Neurosurg. 2016; p. 1-10.

7. Heiss W. Malignant MCA Infarction: Pathophysiology and Imaging for Early Diagnosis and Management Decisions. Cerebrovasc Dis. 2015; 41(1-2): p. 1-7.

8. Baguley I, Nott M, Slewa-Younan S. Long-term mortality trends in functionallydependent adults following severe traumatic-brain injury. 2008. Brain Inj. 2008; 22(12): p. 919-25.

9. Amorim R, de Andrade A, Gattas G, et al. Improved hemodynamic parameters in middle cerebral artery infarction after decompressive craniectomy. Stroke. 2014; 45(5): p. 137580 . 
10. Neugebauer H, Juttler E. Hemicraniectomy for malignant middle cerebral artery infarction: current status and future directions. Int J Stroke. 2014; 9(4): p. 460-7.

11. Kurland D, Khaladj-Ghom A, Stokum J, et al. Complications Associated with Decompressive Craniectomy: A Systematic Review. Neurocrit Care. 2015; 23(2): p. 292304.

12. Vahedi K, Hofmeijer J, Juettler E, et al. Early decompressive surgery in malignant infarction of the middle cerebral artery: a pooled analysis of three randomised controlled trials. Lancet Neurol. 2007; 6(3): p. 215-22.

13. Hofmeijer J, Kappelle L, Algra A, et al. Surgical decompression for space-occupying cerebral infarction (the Hemicraniectomy After Middle Cerebral Artery infarction with Life-threatening Edema Trial [HAMLET]: a multicentre, open, randomised trial. Lancet Neurol. 2009; 8(4): p. 326-33.

14. Cruz-Flores S, Berge E, Whittle I. Surgical decompression for cerebral oedema in acute ischaemic stroke (Review). Cochrane Database of Syst Rev. 2012; 1(CD003435): p. 122.

15. Moher D, Liberati A, Telzlaff J, Altman D, PRISMA Group. Preferred reporting items for systematic reviews and meta-analyses: the PRISMA statement. BMJ. 2009; 339(b2535).

16. Sterne J, Higgins J, Reeves B, Development Group for ACROBAT-NRSI. A Cochrane Risk of Bias Assessment Tool: for Non-Randomised Studies of Interventions (ACROBAT-NRSI). [Online]; 2014. Available from: http://www.riskofbias.info. [cited $0310,2017]$

17. Wells G, Shea B, O'Connell D, et al. The Newcastle-Ottawa Scale (NOS) for assessing the quality if nonrandomized studies in meta-analyses. [Online]; 2014. Available from: http://www.ohri.ca/programs/clinical_epidemiology/oxford.asp. [cited 03 10, 2017]

18. Rankin J. Cerebral vascular accidents in patients over the age of 60: prognosis. Scott Med J. 1957; 2(5): p. 200-15.

19. Juttler E, Unterberg A, Woitzik J, et al. Hemicraniectomy in older patients with extensive middle-cerebral-artery stroke. New Engl J Med. 2014; 370(12): p. 1091-1100.

20. Higgins J, Green S. Cochrane Handbook for Systematic Reviews of Interventions Version 5.1.0. [Online]; 2011. Available from: http://handbook.cochrane.org/.[cited 01 01, 2017] 
21. Juttler E, Schwab S, Schmiedek P, et al. Decompressive Surgery for the treatment of malignant infarction of the middle cerebral artery (DESTINY) a randomized, controlled trial. Stroke. 2007; 38(9): p. 2518-2525.

22. Slezins J, Keris V, Bricis R, et al. Preliminary results of randomized controlled study on decompressive craniectomy in treatment of malignant middle cerebral artery stroke. Medicina (Kaunas). 2012; 48(10): p. 521-4.

23. Chua A, Buckley B, Lapitan M, Jamora R. Acta Medica Phillipina. The National Health Science Journal. [Online]; 2015. Available from: http://actamedicaphilippina.com.ph/content/hemicraniectomy-malignant-middle-cerebralartery-infarction-hemmi-randomized-controlled-clin. [cited 12 12, 2016]

24. Vahedi K, Hofmeijer J, Juttler E, et al. Early decompressive surgery in malignant infarction of the middle cerebral artery: a pooled analysis of three randomised controlled trials. Lancet Neurol. 2007; 6(3): p. 215-22.

25. Vahedi K, Vicaut E, Mateo J, et al. Sequential-design, multicenter, randomized, controlled trial of early decompressive craniectomy in malignant middle cerebral artery infarction (DECIMAL Trial). Stroke. 2007; 38(9): p. 2506-1726.

26. Juttler E, Bosel J, Amiri H, et al. DESTINY II: DEcompressive Surgery for the Treatment of malignant INfarction of the middle cerebral arterY II. Int J Stroke. 2011; 6(1): p. 79-86.

27. World Health Organisation. International Classificaion of Functioning. Geneva: Disability and Health (ICF); 2003.

28. Rahme R, Zuccarello M, Kleindorfer D, Adeoye O, Ringer A. Decompressive hemicraniectomy for malignant middle cerebral artery territory infarction: is life worth living? J Neurosurg. 2012; 117(4): p. 749-54.

29. Vahedi K, Benoist L, Kurtz A, et al. Quality of life after decompressive craniectomy for malignant middle cerebral artery infarction. J Neurol Neurosurg Psychiatry. 2005; 76(8): p. 1181-2.

30. Kelly A, Holloway R. Health state preferences and decision-making after malignant middle cerebral artery infarctions. Neurology. 2010; 75(8): p. 682-7.

31. Lu X, Huang B, Zheng J, et al. Decompressive craniectomy for the treatment of malignant infarction of the middle cerebral artery. Sci Rep. 2014; 4(7070): p. 1-9. 
32. Arac A, Blanchard V, Lee M, Steinberg G. Assessment of outcome following decompressive craniectomy for malignant middle cerebral artery infarction in patients older than 60 years of age. Neurosurg Focus. 2009; 26(6): p. E333.

33. Yu P, Tian Q, Wen X, Zhang Z, Jiang R. Analysis of Long-Term Prognosis and Prognostic Predictors in Severe Brain Injury Patients Undergoing Decompressive Craniectomy and Standard Care. J Craniofac Surg. 2015; 26(7): p. e635-41.

34. Qureshi A, Suarez J, Yahia A, et al. Timing of neurologic deterioration in massive middle cerebral artery infarction: a multicenter review. Crit Care Med. 2003; 31: p. 272-7.35.

35. Frank J, Schumm L, Wroblewski K, et al. Hemicraniectomy and durotomy upon deterioration from infarction-related swelling trial: randomized pilot clinical trial. Stroke. 2014; 45(3): p. 781-7.

36. Guerts M, van der Worp H, Kappelle L, et al. Surgical Decompression for SpaceOccupying Cerebral Infarction Outcomes at 3 Years in the Randomized HAMLET Trial. Stroke. 2013; 44(9): p. 2506-8

37. Zhao J, Su Y, Zhang Y, et al. Decompressive hemicraniectomy in malignant middle cerebral artery infarct: a randomized controlled trial enrolling patients up to 80 years old. Neurocrit Care. 2012; 17(2): p. 161-71.

38. Raffiq M, Haspani M, Kandasamy R, Abdullah J. Decompressive craniectomy for malignant middle cerebral artery infarction: Impact on mortality and functional outcome. Surg Neurol Int. 2014; 5(102).

39. Sengeze N, Kutluhan S, Karaaslan T. Comparison of the decompressive surgery and medical therapy alone results in malignant middle cerebral artery infarction. J Neurol Sci. Turkish. 2016; 33(2 \#48): p. 296-308.

40. Akins P, Axelrod Y, Arshad S, Guppy K. Initial conservative management of severe hemispheric stroke reduces decompressive craniectomy rates. Neurocrit Care. 2016; 25(1): p. 3-9. 
Gul et al., 2018

\section{FIGURE LEGENDS}

Figure 1: PRISMA flow diagram for MCI studies. Adapted from Moher, et al., (2009). Preferred Reporting Items for Systematic Reviews and Meta-Analyses: The PRISMA statement.

Figure 2a: Forest plot with OR estimating with $95 \%$ CI for the mortality outcome (defined as $\mathbf{m R S}=\mathbf{6}$ ) associated with DC versus BMT for studies grouped into RCTs and NRTs, and their pooled results at 3 months, 6 months, 12 months and 3 years follow-up. CI, confidence interval; DC: Decompressive craniectomy; BMT: best medical therapy; OR, odds ratio; mRS: modified Rankin Scale; IV: inverse variance; RCT: randomised controlled trials; NRTs: non-randomised trials.

Figure 2b: Forest plot with OR estimating with 95\% CI for unfavourable outcome (defined as $\mathbf{m R S}=\mathbf{5}$ ) associated with DC versus BMT for studies grouped into RCTs and NRTs, and their pooled results at 3 months, 6 months, 12 months and 3 years follow-up. CI, confidence interval; DC: decompressive craniectomy; BMT: best medical therapy; OR, odds ratio; mRS: modified Rankin scale; IV: inverse variance; RCT: randomised controlled trials; NRTs: non-randomised trials.

Figure 3: Forest plot with OR estimating with $95 \%$ CI for (A) mortality outcome and (B) unfavourable outcome (defined as $\mathbf{m R S}=\mathbf{5}$ ) associated with DC versus BMT for individual studies and subgroup population stratified by age at 6 months follow-up.

CI, confidence interval; DC: decompressive craniectomy; BMT: best medical therapy; OR, odds ratio; mRS: modified Rankin scale; IV: inverse variance.

Figure 4: Funnel plot for assessment of publication bias. No obvious asymmetry was detected. OR: odds ratios, SE: standard error, logOR: Natural logarithm of the OR. 


\section{APPENDIX}

\section{Search Strategy}

\section{CENTRAL/ MEDLINE Searched August 2018}

1. stroke $\$$ or cerebral vascular or cerebrovasc $\$$ or cva

2. cerebrovascular disorders/ or cerebrovascular disease/ or brain ischemia/ or hypoxiaischemia, brain/ or carotid artery diseases/ or carotid artery, internal, dissection/ or intracranial arterial diseases/ or cerebral arterial diseases/ or "intracranial embolism and thrombosis"/ or intracranial embolism/ or intracranial thrombosis/ or stroke/

3. exp brain infarction/

4. (brain or cerebral or intracranial) near3 (oedema or edema or swell*)

5. MeSH descriptor Decompression, Surgical explode all trees

\section{EMBASE: searched August 2018}

1. cerebrovascular disorders/ or cerebrovascular disease/ or brain ischemia/ or hypoxiaischemia, brain/ or carotid artery diseases/ or carotid artery, internal, dissection/ or intracranial arterial diseases/ or cerebral arterial diseases/ or intracranial embolism/ or intracranial thrombosis/ or intracranial embolism/ or stroke/

2. stroke $\$$ or cerebral vascular or cerebrovasc $\$$ or cva

decompress\$ or craniectom\$ or craniotom\$ or hemi?craniect\$ or trepa $\$$ or treph 


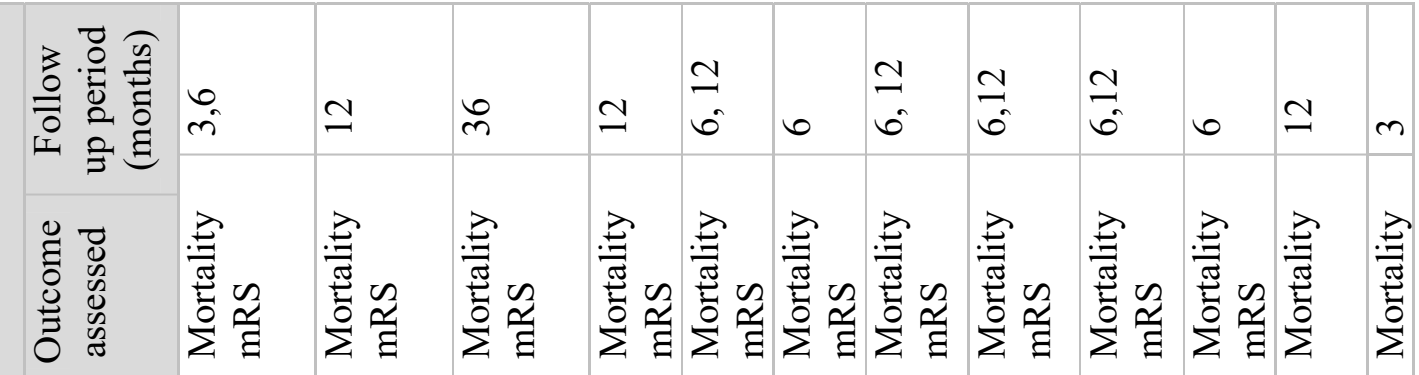

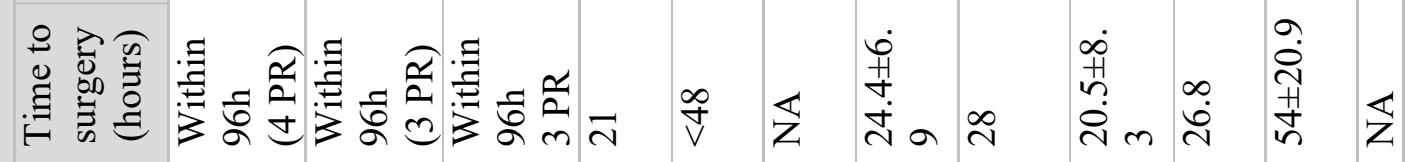

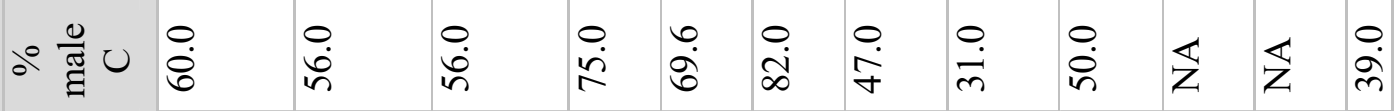

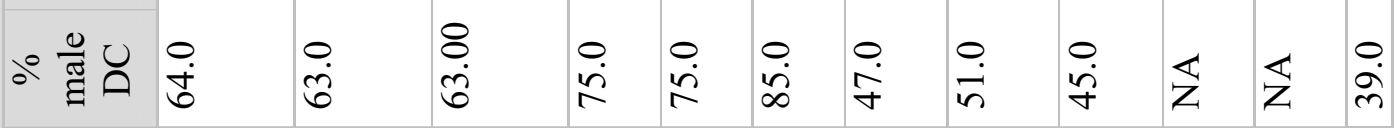

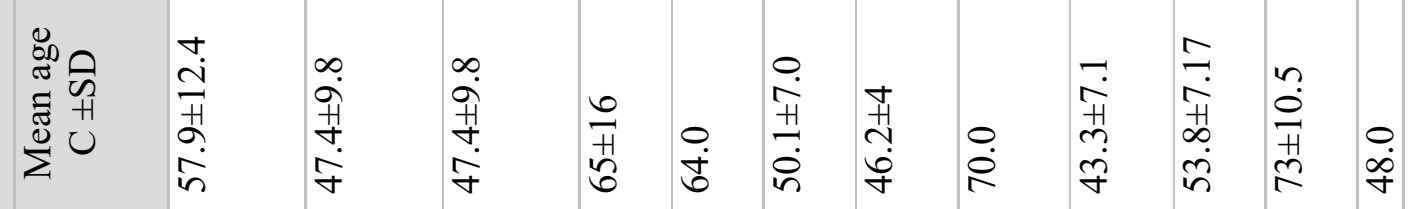

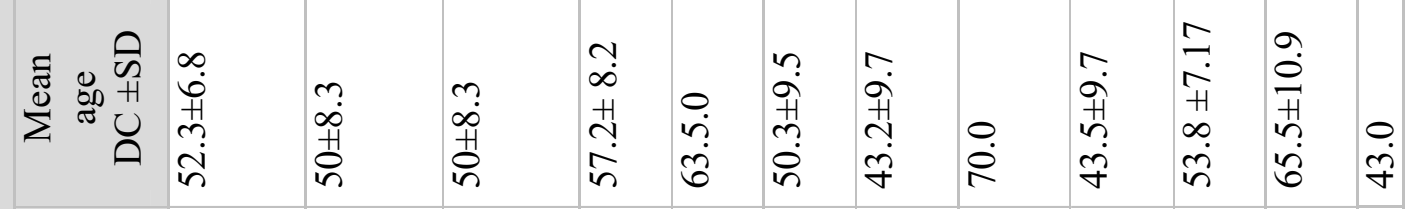

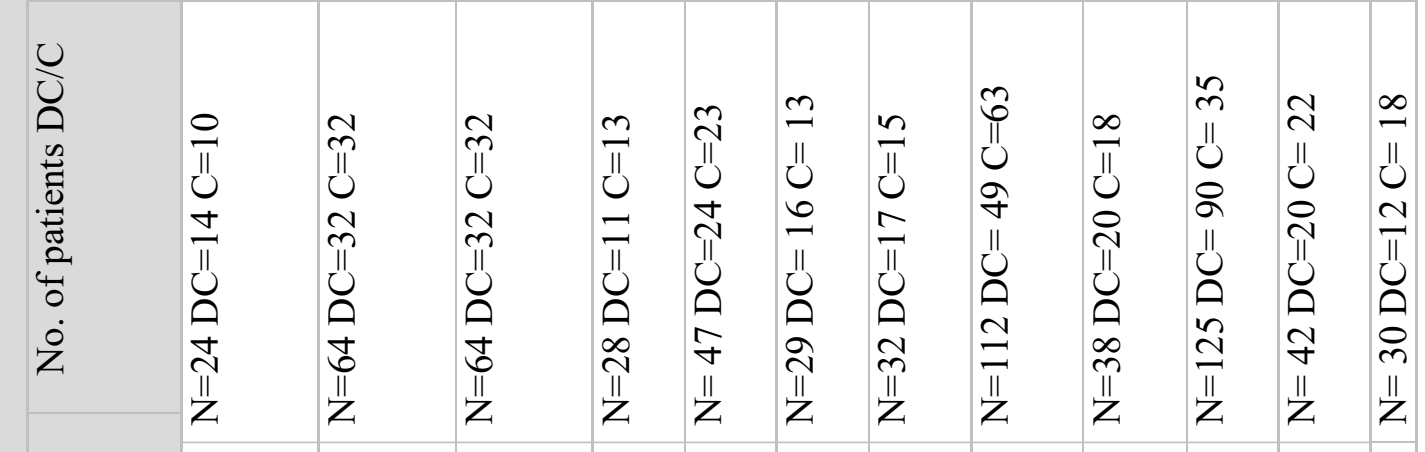

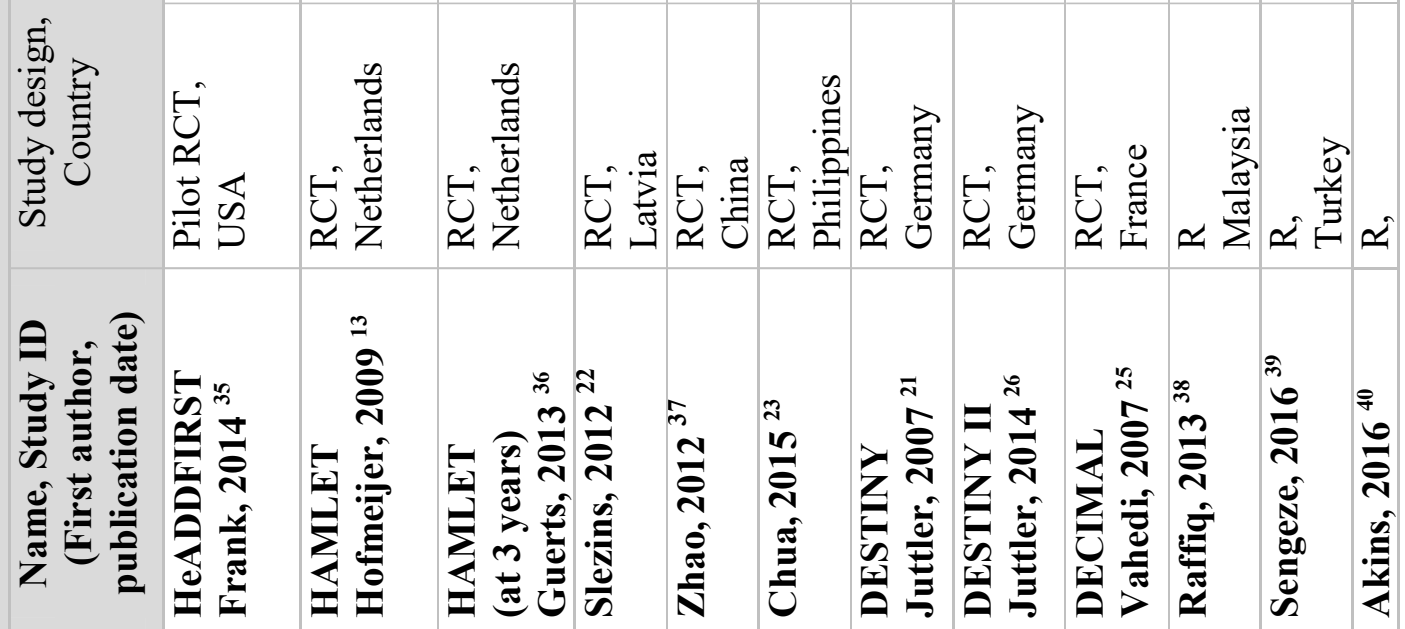




\begin{tabular}{|c|c|c|c|c|c|c|}
\hline 0 & $\begin{array}{l}7 \\
0 \\
0 \\
\end{array}$ & 0 & $m$ & 0 & $m$ & 兽 \\
\hline 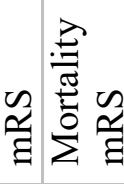 & & 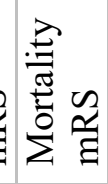 & & & & \\
\hline$\stackrel{\infty}{+}$ & in & $\stackrel{\infty}{q}$ & $\begin{array}{l}\hat{\pi} \\
\vec{i} \\
\text { i }\end{array}$ & $\stackrel{\infty}{+}$ & 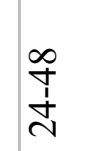 & \\
\hline in & 8 & $\frac{m}{q}$ & $\stackrel{+}{\stackrel{+}{R}}$ & ठें & î̀ & \\
\hline $\begin{array}{l}\dot{0} \\
\dot{\infty} \\
\dot{\sigma}\end{array}$ & $\begin{array}{l}8 \\
i \\
i \\
i\end{array}$ & $\stackrel{m}{8}$ & $\begin{array}{l}8 \\
\stackrel{0}{\circ} \\
\text { n. }\end{array}$ & in & $\begin{array}{l}R \\
6 \\
i n \\
i n\end{array}$ & \\
\hline $\begin{array}{l}\infty \\
\tilde{j} \\
\vec{n} \\
\dot{n} \\
i\end{array}$ & 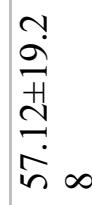 & 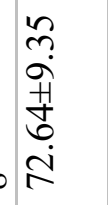 & 3 & 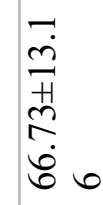 & $\underset{0}{\frac{\vec{H}}{\mathrm{~m}}}$ & \\
\hline $\begin{array}{l}\infty \\
n \\
\\
\hat{n} \\
\vdots \\
b\end{array}$ & 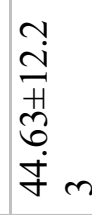 & $\begin{array}{l}\stackrel{0}{0} \\
\stackrel{i}{i} \\
\stackrel{H}{H} \\
\end{array}$ & $\stackrel{\infty}{n}$ & $\begin{array}{l}\infty \\
\infty \\
0 \\
m \\
\text { तु } \\
0\end{array}$ & $\begin{array}{l}n \\
\stackrel{n}{n} \\
\tilde{n} \\
n\end{array}$ & \\
\hline 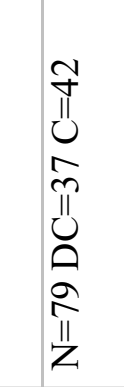 & 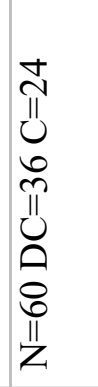 & 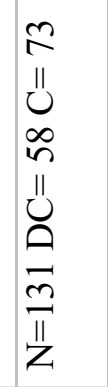 & 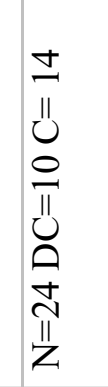 & 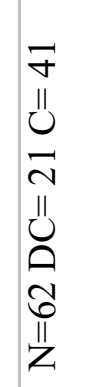 & 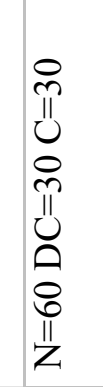 & z \\
\hline & & & & & & \\
\hline 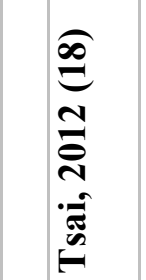 & 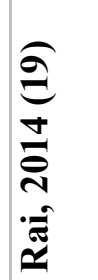 & 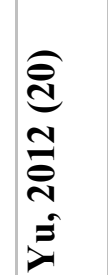 & 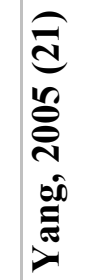 & 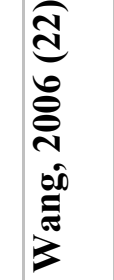 & 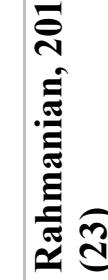 & 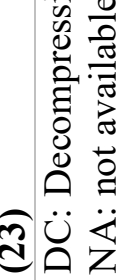 \\
\hline
\end{tabular}




\begin{tabular}{|c|c|c|c|c|c|c|}
\hline $\begin{array}{l}\text { Type } \\
\text { of DC }\end{array}$ & $\begin{array}{l}\text { Follow- } \\
\text { up }\end{array}$ & Outcome & $\begin{array}{l}\text { No. of } \\
\text { studies }\end{array}$ & $\begin{array}{l}\text { No. of } \\
\text { participant } \\
\text { s }\end{array}$ & OR (95\% CI) & P value \\
\hline \multirow{8}{*}{$\begin{array}{l}\text { Early } \\
<48 h\end{array}$} & \multirow{2}{*}{$\begin{array}{l}3 \\
\text { months }\end{array}$} & mortality & 2 & 120 & $0.10[0.04,0.23]^{*}$ & $<0.00001$ \\
\hline & & $\mathrm{mRS}=5$ & 2 & 84 & $0.51[0.14,1.86]$ & 0.31 \\
\hline & \multirow{2}{*}{$\begin{array}{l}6 \\
\text { months }\end{array}$} & mortality & 9 & 686 & $0.22[0.13,0.39]^{*}$ & $<0.00001$ \\
\hline & & $\mathrm{mRS}=5$ & 6 & 416 & $0.89[0.31,2.56]$ & 0.83 \\
\hline & \multirow{2}{*}{$\begin{array}{l}12 \\
\text { months }\end{array}$} & mortality & 6 & 310 & $0.15[0.09,0.26]^{*}$ & $<0.00001$ \\
\hline & & $\mathrm{mRS}=5$ & 2 & 106 & $0.36[0.08,1.57]$ & 0.82 \\
\hline & \multirow[t]{2}{*}{3 years } & mortality & 1 & 39 & $0.09[0.02,0.40]^{*}$ & 0.002 \\
\hline & & $\mathrm{mRS}=5$ & 1 & 39 & $2.71[0.10,70.65]$ & 0.55 \\
\hline \multirow{8}{*}{$\begin{array}{l}\text { Late } \\
\text { DC } \\
>48 h\end{array}$} & \multirow{2}{*}{$\begin{array}{l}3 \\
\text { months }\end{array}$} & mortality & 2 & 48 & $0.26[0.02,3.28]$ & 0.30 \\
\hline & & $\mathrm{mRS}=5$ & 1 & 24 & $0.56[0.11,2.90]$ & 0.49 \\
\hline & \multirow{2}{*}{$\begin{array}{l}6 \\
\text { months }\end{array}$} & mortality & 1 & 24 & $0.83[0.16,4.44]$ & 0.83 \\
\hline & & $\mathrm{mRS}=5$ & 1 & 24 & $1.30[0.23,7.38]$ & 0.77 \\
\hline & \multirow{2}{*}{$\begin{array}{l}12 \\
\text { months }\end{array}$} & mortality & 2 & 106 & $0.36[0.08,1.57]$ & 0.17 \\
\hline & & $\mathrm{mRS}=5$ & 1 & 64 & $\begin{array}{l}15.94 \quad[0.86, \\
296.1]\end{array}$ & 0.06 \\
\hline & \multirow[t]{2}{*}{3 years } & mortality & 1 & 24 & $0.57[0.10,3.18]$ & 0.52 \\
\hline & & $\mathrm{mRS}=5$ & 1 & 24 & Not estimable & \\
\hline
\end{tabular}

DC: Decompressive craniectomy, $\mathrm{mRS}=$ modified Rankin Scale, OR: odds ratio, CI: confidence interval. Bold font $=$ statistical significance 
Table 3 Summary of results and sensitivity analyses for mortality and unfavourable outcome.

\begin{tabular}{|c|c|c|c|c|c|c|}
\hline $\begin{array}{l}\text { Study } \\
\text { subgroup }\end{array}$ & $\begin{array}{l}\text { No. of } \\
\text { studies }\end{array}$ & $\begin{array}{l}\text { No. of } \\
\text { patients }\end{array}$ & $\begin{array}{l}\text { Statistical } \\
\text { method }\end{array}$ & $\begin{array}{l}\text { Effect estimate } \\
(95 \% \mathrm{Cl})\end{array}$ & P value & $\mathbf{I}^{2}$ \\
\hline \multicolumn{7}{|c|}{ Summary: mortality } \\
\hline 3 months & 4 & 138 & $\begin{array}{l}\text { OR (IV, Random, } \\
95 \% \text { CI) }\end{array}$ & $\begin{array}{l}0.23(0.07 \\
0.71)^{*}\end{array}$ & 0.01 & $38 \%$ \\
\hline 6 months & 11 & 734 & $\begin{array}{l}\text { OR (IV, Random, } \\
95 \% \mathrm{CI})\end{array}$ & $\begin{array}{l}0.25(0.15 \\
0.43)^{*}\end{array}$ & $<0.00001$ & $54 \%$ \\
\hline 12 months & 8 & 416 & $\begin{array}{l}\text { OR (IV, Random, } \\
95 \% \mathrm{CI})\end{array}$ & $\begin{array}{l}0.18(0.11 \\
0.29)^{*}\end{array}$ & $<0.00001$ & 0 \\
\hline 3 years & 1 & 63 & $\begin{array}{l}\text { OR (IV, Random, } \\
95 \% \text { CI) }\end{array}$ & $\begin{array}{l}0.21(0.07 \\
0.61)^{*}\end{array}$ & 0.004 & NA \\
\hline
\end{tabular}

\section{Summary: unfavourable outcome}

\begin{tabular}{|l|l|l|l|l|l|l|}
\hline 3 months & 3 & 108 & $\begin{array}{l}\text { OR (IV, Random, } \\
95 \% \text { CI })\end{array}$ & $\begin{array}{l}0.53(0.19, \\
1.46)\end{array}$ & 0.22 & 0 \\
\hline 6 months & 8 & 464 & $\begin{array}{l}\text { OR (IV, Random, } \\
95 \% \text { CI })\end{array}$ & $\begin{array}{l}1.03(0.43, \\
2.47)\end{array}$ & 0.94 & $58 \%$ \\
\hline 12 months & 7 & 374 & $\begin{array}{l}\text { OR (IV, Random, } \\
95 \% \text { CI })\end{array}$ & $\begin{array}{l}1.38(0.47, \\
4.11)\end{array}$ & 0.56 & $39 \%$ \\
\hline 3 years & 1 & 63 & $\begin{array}{l}\text { OR (IV, Random, } \\
95 \% \text { CI) }\end{array}$ & $\begin{array}{l}3.20(0.13, \\
81.50)\end{array}$ & 0.48 & NA \\
\hline
\end{tabular}

Sensitivity analyses for the mortality outcome excluding NRTs

\begin{tabular}{|l|l|l|l|l|l|l|}
\hline $\begin{array}{l}3 \text { months } \\
\text { RCTs }\end{array}$ & 1 & 24 & $\begin{array}{l}\text { OR (IV, Random, } \\
95 \% \text { CI })\end{array}$ & $\begin{array}{l}0.83[0.16, \\
4.44]\end{array}$ & 0.83 & NA \\
\hline $\begin{array}{l}6 \text { months } \\
\text { RCTs }\end{array}$ & 6 & 277 & $\begin{array}{l}\text { OR (IV, Random, } \\
95 \% \text { CI })\end{array}$ & $\begin{array}{l}0.22[0.12, \\
0.40]^{*}\end{array}$ & $<\mathbf{0 . 0 0 0 0 1}$ & $18 \%$ \\
\hline $\begin{array}{l}12 \text { months } \\
\text { RCTs }\end{array}$ & 6 & 314 & $\begin{array}{l}\text { OR (IV, Random, } \\
95 \% \text { CI })\end{array}$ & $\begin{array}{l}0.17[0.10, \\
0.28]^{*}\end{array}$ & $<\mathbf{0 . 0 0 0 0 1}$ & $0 \%$ \\
\hline
\end{tabular}

\begin{tabular}{l|l|l|l|l|l|l|}
\hline $\begin{array}{l}\text { Sensitivity analyses for the unfavourable outcome excluding NRTs } \\
\begin{array}{l}3 \text { months } \\
\text { RCTs }\end{array}\end{array}$ & 1 & 24 & $\begin{array}{l}\text { OR (IV, Random, } \\
95 \% \text { CI) }\end{array}$ & $\begin{array}{l}0.56[0.11, \\
2.90]\end{array}$ & 0.49 & NA \\
\hline $\begin{array}{l}6 \text { months } \\
\text { RCTs }\end{array}$ & 6 & 277 & $\begin{array}{l}\text { OR (IV, Random, } \\
95 \% \text { CI) }\end{array}$ & $\begin{array}{l}1.79[0.92, \\
3.48]\end{array}$ & 0.08 & 0 \\
\hline $\begin{array}{l}12 \text { months } \\
\text { RCTs }\end{array}$ & 6 & 314 & $\begin{array}{l}\text { OR (IV, Random, } \\
95 \% \text { CI) }\end{array}$ & $\begin{array}{l}1.50[0.36, \\
6.22]\end{array}$ & 0.58 & $52 \%$ \\
\hline
\end{tabular}

$\mathrm{OR}=$ Odds ratio; $\mathrm{IV}=$ inverse variance; $\mathrm{CI}=$ confidence interval; $\mathrm{NA}=$ heterogeneity not applicable as only one study has been pooled; $\mathrm{I}^{2}=$ heterogeneity $*=$ statistical significance 


\section{Figure(s)}

Click here to download high resolution image

\section{PRISMA 2009 Flow Diagram}
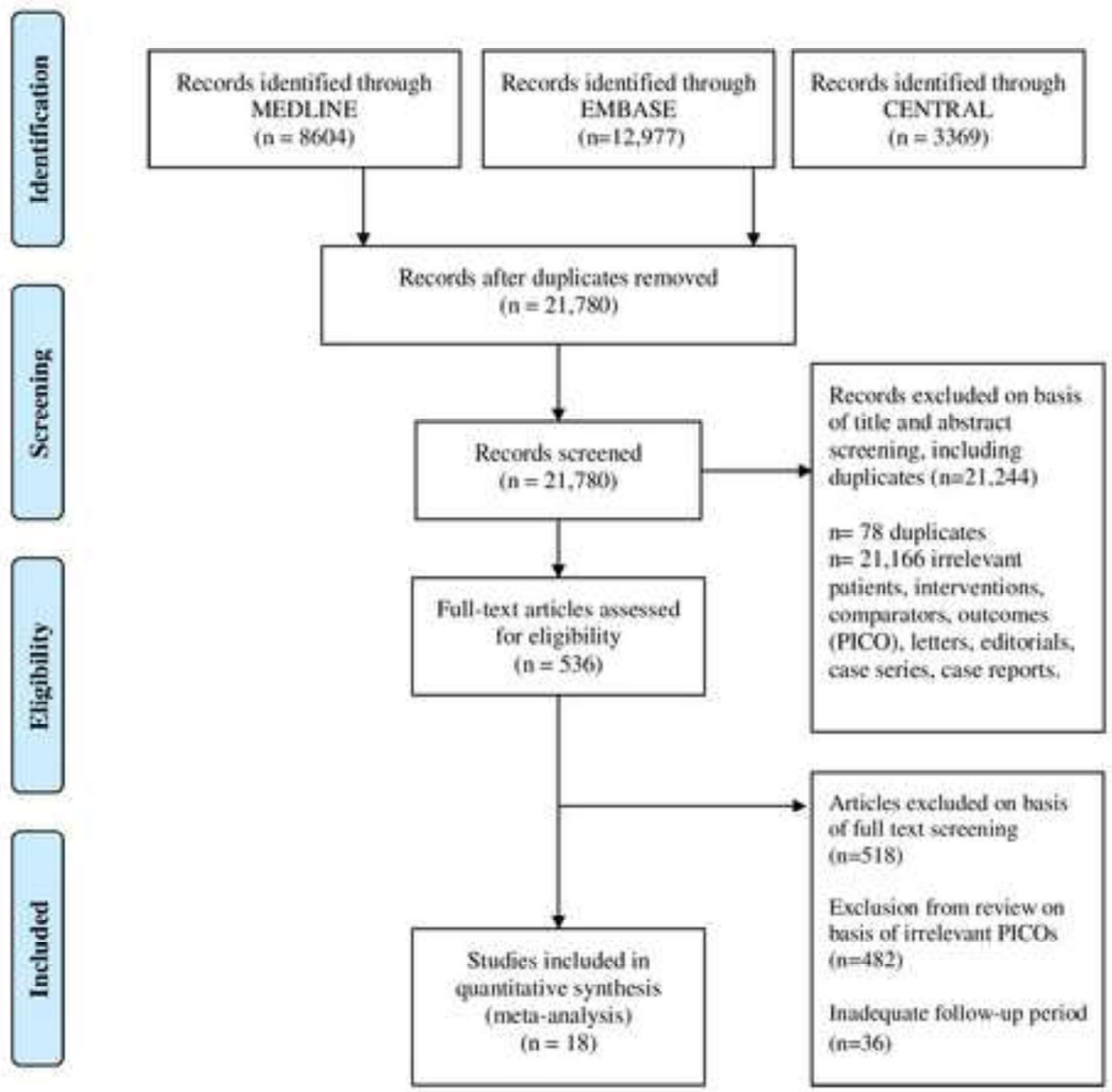


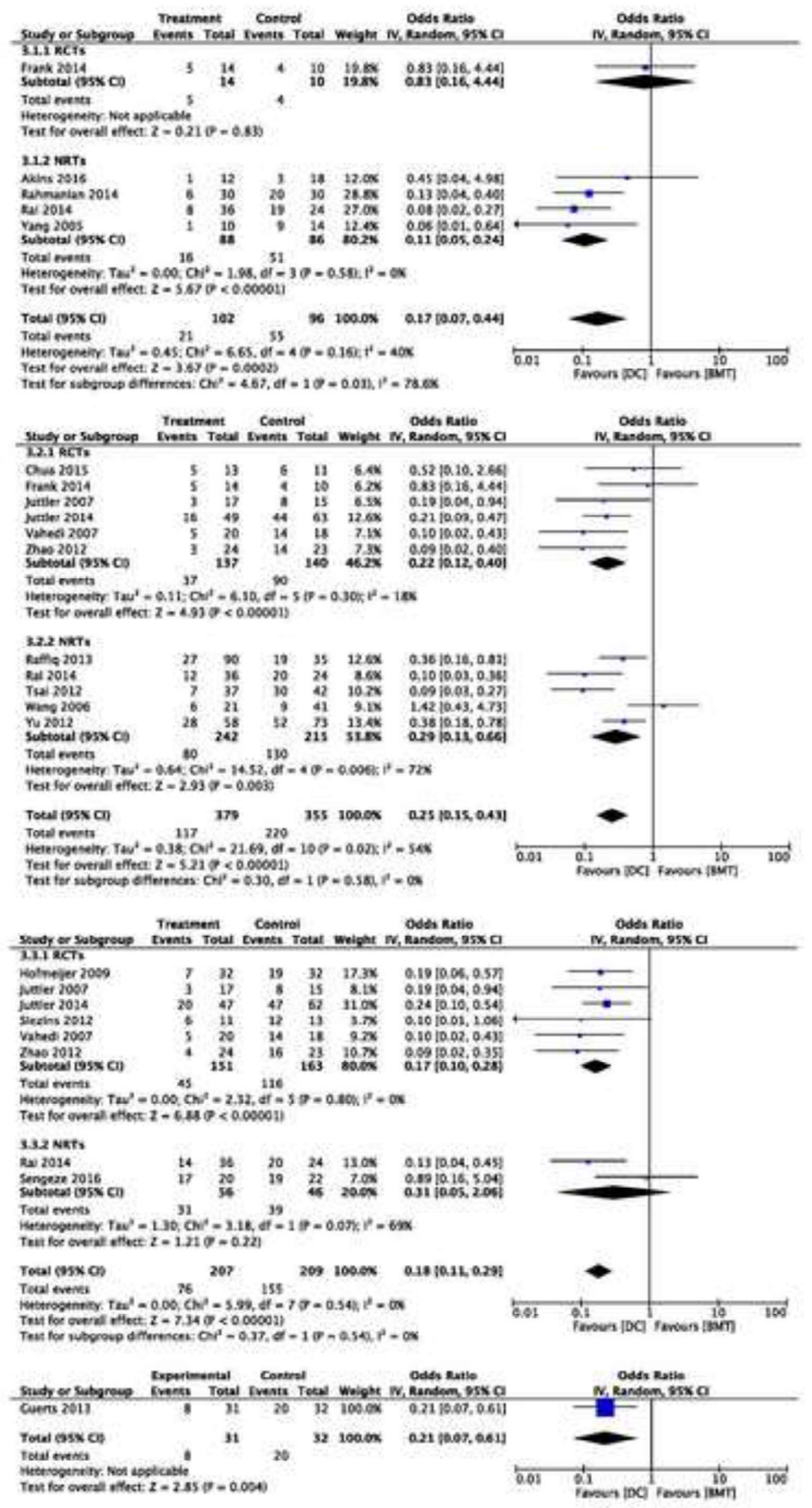

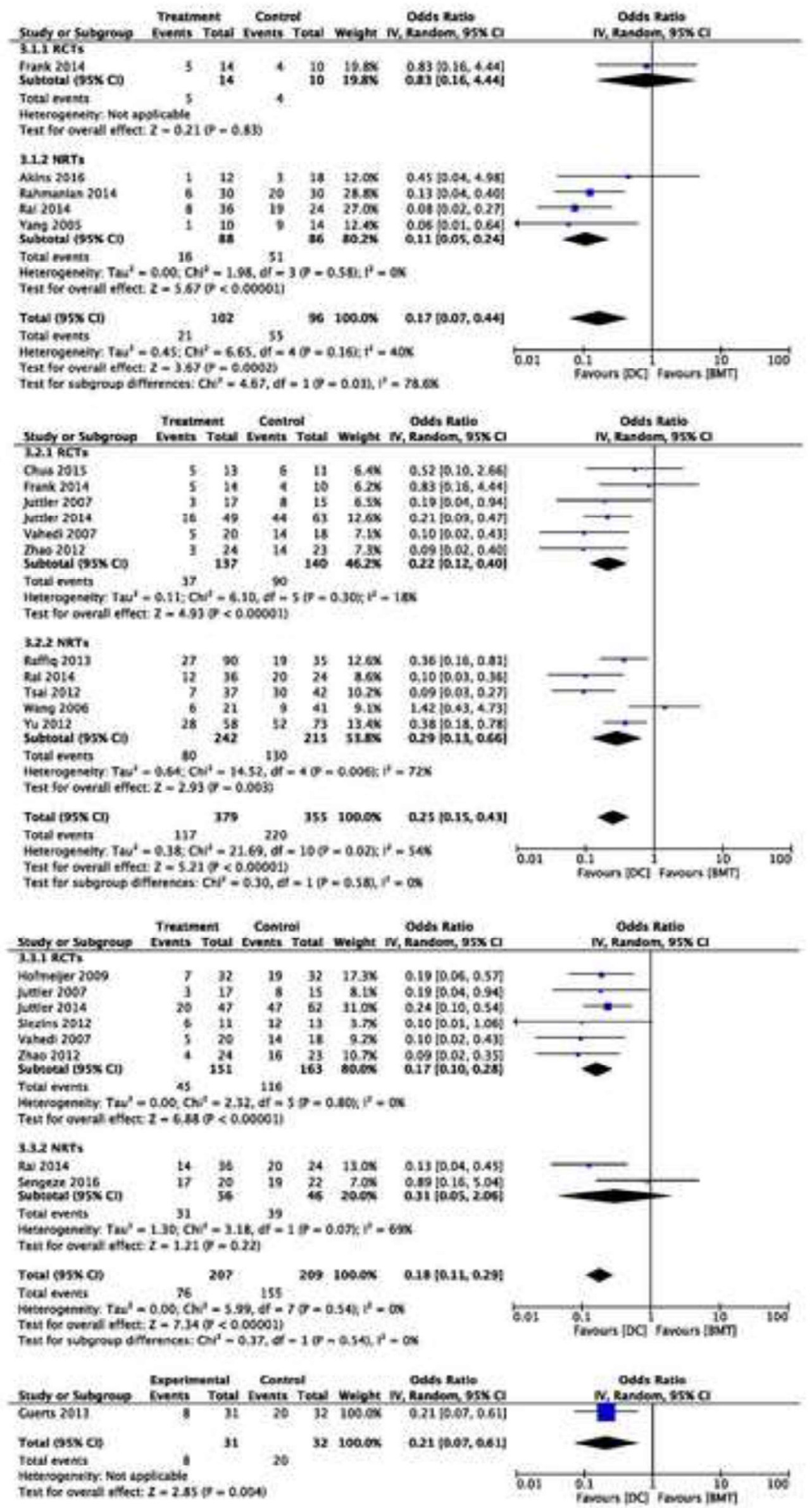

Twelve months follow

Three years follow up

\section{Six months follow up}

Three months follow up

\section{$\sqrt{3}$}$$
\text { (2) }
$$$$
\sqrt{2}
$$

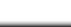

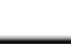

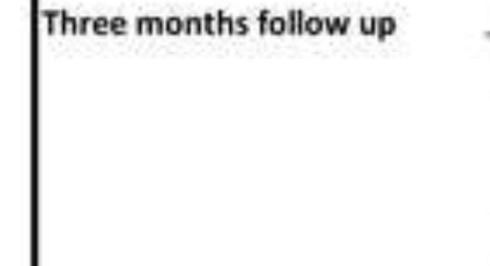


Three months follow up

Six months follow up

Twelve months follow

Three years follow up

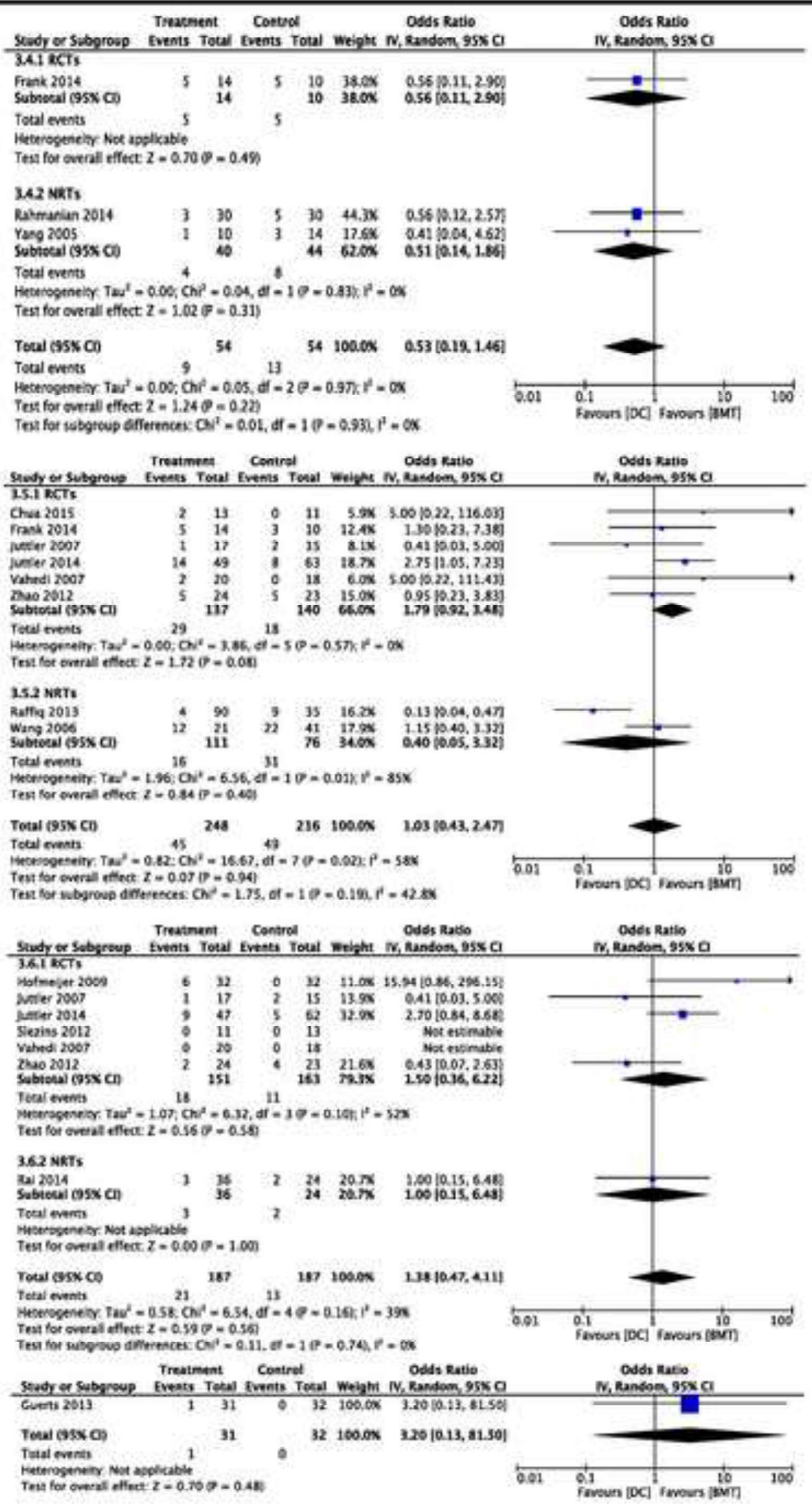


A

\begin{tabular}{|c|c|c|c|c|c|c|c|c|c|}
\hline \multirow{2}{*}{$\begin{array}{l}\text { Study or Subgroup } \\
4.1 .1 \text { age }<60\end{array}$} & $\begin{array}{l}\text { Experime } \\
\text { Events }\end{array}$ & $\begin{array}{l}\text { ental } \\
\text { Total }\end{array}$ & \multicolumn{2}{|c|}{ Control } & Weight & $\begin{array}{l}\text { Odds Ratio } \\
\text { IV, Random, } 95 \% \mathrm{CI}\end{array}$ & & \multicolumn{2}{|c|}{$\begin{array}{c}\text { Odds Ratio } \\
\text { IV, Random, } 95 \times \mathrm{Cl}\end{array}$} \\
\hline & & & & & & & & & \\
\hline Chua 2015 & 5 & 13 & 6 & 11 & $8.4 x$ & $0.52(0.10,2.66)$ & & & \\
\hline Juttler 2007 & 3 & 17 & 8 & 15 & $8.6 \%$ & $0.19[0.04,0.94]$ & & & \\
\hline Raffiq 2013 & 27 & 90 & 19 & 35 & $22.6 x$ & $0.36[0.16,0.81]$ & & - & \\
\hline Tsal 2012 & 10 & 18 & 2 & 4 & $5.1 x$ & $1.25[0.14,10.94]$ & & & \\
\hline Vahedi 2007 & 5 & 20 & 14 & 18 & $9.6 \mathrm{X}$ & $0.10[0.02,0.43]$ & & & \\
\hline $\begin{array}{l}\text { Zhao } 2012 \\
\text { Subtotal ( } 95 \% \mathrm{CD})\end{array}$ & 1 & $\begin{array}{r}8 \\
166\end{array}$ & 6 & $\begin{array}{l}10 \\
93\end{array}$ & $\begin{array}{r}4.1 x \\
58.5 \%\end{array}$ & $\begin{array}{l}0.10[0.01,1.10] \\
0.28[0.15,0.54]\end{array}$ & 4 & & \\
\hline \multicolumn{10}{|c|}{$\begin{array}{l}\text { Heterogeneity Tau }{ }^{2}=0.08 ; C h l^{2}=5.71 \text {, df }=5(P-0.34) ; 1^{2}=12 x \\
\text { Test for averall effect: } Z=3.86(P=0.0001)\end{array}$} \\
\hline \multicolumn{10}{|l|}{4.1 .2 age $>60$} \\
\hline Jutuler 2014 & 16 & 49 & 44 & 63 & $22.6 \mathrm{x}$ & $0.21(0.09,0.47)$ & & & \\
\hline Tsal 2012 & 4 & 24 & 28 & 38 & 12.18 & $0.07(0.02,0.26)$ & & & \\
\hline $\begin{array}{l}\text { Zhao } 2012 \\
\text { Subtotal ( } 95 \mathrm{~K} \mathrm{CD})\end{array}$ & 2 & $\begin{array}{l}16 \\
89\end{array}$ & 8 & 114 & $\begin{array}{r}6.88 \\
41.5 \%\end{array}$ & $\begin{array}{l}0.09[0.01,0.57] \\
0.14[0.07,0.28)\end{array}$ & & & \\
\hline \multicolumn{10}{|c|}{$\begin{array}{l}\text { Total tvents } \\
\left.\text { Heterogenteity: Taur }=0.04 ; \text { Chi }^{2}=2.22 \text {, of }=20=0.33\right) ; r^{2}=10 \% \\
\text { Test for overall effect: } Z=5.51(\mathrm{P}<0.00001)\end{array}$} \\
\hline Total (95*C) & & 255 & & 207 & $100.0 \%$ & $0.21[0.12,0.35]$ & & & \\
\hline Total events & 73 & & 135 & & & & & & \\
\hline $\begin{array}{l}\text { Heterogeneity: } \operatorname{Tau}^{2} \\
\text { Test for overall effect: } \\
\text { Test for subgroup diff }\end{array}$ & $\begin{array}{l}0.14 ; \mathrm{Chi}^{2} \\
z=5.95 \\
\text { erences: } \mathrm{C}\end{array}$ & $\begin{array}{l}2=10.4 \\
0 \times 0.0 \\
h i^{2}=2\end{array}$ & $\begin{array}{l}\text { 49, df = } \\
00001) \\
15 \text {, df }=\end{array}$ & $8(P=C$ & $\begin{array}{l}0.23) ; 1^{2}= \\
0.14), \mathrm{f}^{2}\end{array}$ & $\begin{array}{l}=24 x \\
=53.5 x\end{array}$ & 0.01 & 0.1 & $\frac{10}{\text { Favours [BMT] }}$ \\
\hline
\end{tabular}

B

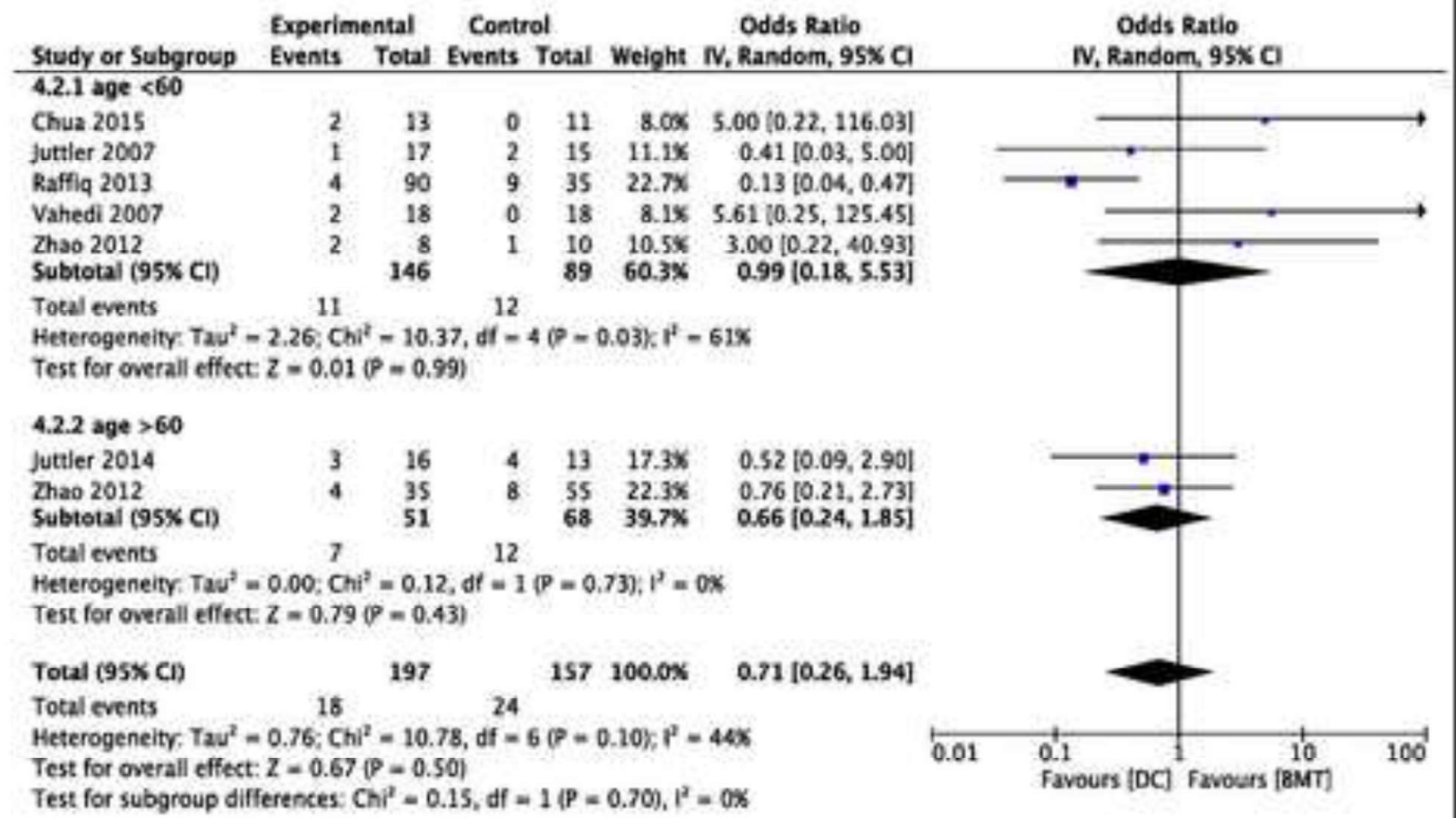




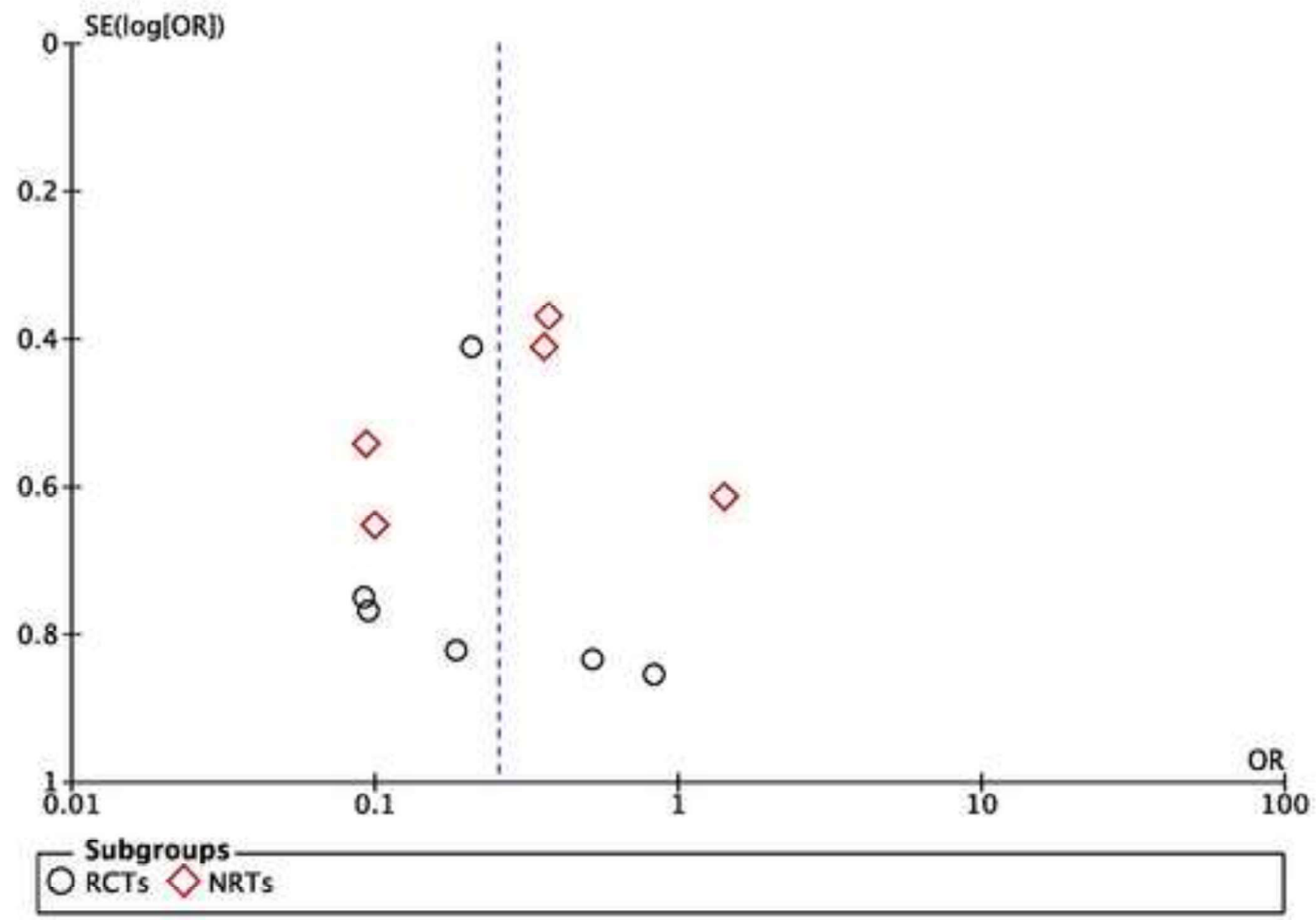


Click here to download Supplementary Material (Video/Media Files): Supplementary Tables.docx

Supplementary Material (Video/Media Files)
Click here to download Supplementary Mate 